\title{
EXPERIMENTOS FÍSICOS COM MATERIAIS ANALÓGICOS ALTERNATIVOS APLICADOS À EVOLUÇÃO TECTÔNICA NEOARQUEANA DO QUADRILÁTERO FERRÍFERO
}

\author{
CAROLINE JANETTE SOUZA GOMES* MAURÍCIO ANTÔNIO CARNEIRO**, ISSAMU ENDO***, MARCO \\ ANTÔ NIO FONSECA***** \& GESNER JOSÉ ILÁ RIO DOS SANTOS******
}

\begin{abstract}
PHYSICAL MODELS WITH ALTERNATIVE ANALOGUE MATERIALS APLICATED TO THE NEOARCHEAN TECTONIC EVOLUTION OF THE QUADRILÁTERO FERRÍFERO Physical models have been used to simulate the transpressional tectonic model for the Neoarchean in the Quadrilátero Ferrífero. In ali experiments the Rio das Velhas Supergroup is modelled using viscous silicone, and the sialic basement is simulated by distinct materiais. Dry sand represents the brittle behavior, and two different mixtures of silicone and graphite model ductil crusts. This study dicusses the structures formed under the three distinct rheologies. The dextral transpression produces a structural pattern in good agreement with that of nature: rotation of flow lines to the NS direction, and their disposition around the Bação Metamorphic Complex, in the Quadrilátero Ferrífero. In addition, foliation triple points are shown at the northwest and southeast corners of the Complex.
\end{abstract}

Key-words: transpression, dextral strike slip, Bação Metamorphic Complex, alternative modeling material: mixtures of silicone and graphite

RESUMO Em três experimentos de modelagem física foi testado um modelo transpressional para a tectônica neoarqueana do Quadrilátero Ferrífero. A crosta siálica é simulada em um modelo por areia seca, rúptil, e, nos dois outros, por material viscoso constituído por misturas de silicone e grafite, na proporção $3: 1 \mathrm{e} 1: 1$. Silicone puro modela em todos os experimentos a sequência supracrustal do Supergrupo Rio das Velhas. O estudo discute as implicações das diferentes reologias em cada um dos experimentos que apontam para uma deformação transpressiva no Neoarqueano. Um cisalhamento direcional dextral causa, nos experimentos, o arrasto das linhas de fluxo para a direção NS e em torno do Complexo Metamórfico do Bação, gerando pontos tríplices da foliação na região NW e SE. Obtem-se, nos experimentos, um quadro estrutural muito parecido com aquele observado hoje no domínio do Complexo Metamórfico do Bação, no centro do Quadrilátero Ferrífero.

Palavras-chaves: transpressão, cisalhamento direcional dextral, Complexo Metamórfico do Bação, materiais analógicos: areia e misturas de silicone com grafite

INTRODUÇÃO O Quadrilátero Ferrífero (QF) localiza-se na porção meridional do Cráton São Francisco e é constituído por três grandes unidades litoestratigráficas: terrenos granitognáissicos de idade arqueana, constituindo um complexo metamórfico, e duas espessas sequências supracrustais. As sequências supracrustais compreendem o Supergrupo Rio das Velhas (SRV), neoarqueano, e o Supergrupo Minas (SM) e o Grupo Itacolomi, proterozóicos (Fig. 1). O complexo metamórfico, conhecido por inúmeras denominações locais ("Bonfim", "Belo Horizonte", "Caeté", "Santa Bárbara", "Bação" etc), constitui uma suite do tipo TTG (Figueiredo \& Barbosa 1993), parcialmente migmatizada, com frequentes intrusões de granitóides e anfibolitos assim como veios de pegmatitos. Herz (1970), Roeser et al. (1987) e Carneiro (1992) determinaram para os complexos condições metamórficas de fácies anfibolito que, no Complexo Metamórfico do Bação, chega a fácies anfibolito alta com temperaturas da ordem de $700^{\circ} \mathrm{C}$ (Gomes, N. 1985).

O SRV é composto por rochas vulcanossedimentares que caracterizam um cinturão de rochas verdes, metamorfizadas na fácies xisto-verde a anfibolito, com temperaturas de 400 a $600^{\circ} \mathrm{C}$, e com evidências de retrometamorfismo na fácies xisto-verde (Golia 1977).

O SM (grupos Caraça, Itabira, Piracicaba e Sabará) e o Grupo Itacolomi constituem um pacote metassedimentar, metamorfizado na fácies xisto-verde. $\mathrm{O}$ pacote possui ca. $7.000 \mathrm{~m}$ de espessura e é caracterizado por material elástico e químico, que inclui as ricas formações ferríferas bandadas do tipo Lago Superior (Grupo Itabira). Renger et al. (1994) e Carneiro et al. (1995) descrevem para a nucleação e o preenchimento das "Bacias Minas", proterozóicas, dois ciclos tectonossedimentares relacionando-os, respectivamente, a um evento pré-Transamazônico e outro Transamazônico.

$\mathrm{O}$ contato entre as três grandes unidades litoestratigráficas do QF é, em geral, fortemente tectonizado, registrando-se, no entanto, localmente um contato intrusivo entre as duas unidades mais antigas (Herz 1970).

O crescente número de levantamentos sistemáticos das estruturas regionais, assim como os mapeamentos litoestratigráficos nos complexos metamórficos e os novos dados geocronológicos, tem contribuído muito para a elucidação da complexa história polifásica de Arqueano e Proterozóico do QF (Carneiro 1992; Noce et al 1994; Teixeira et al. 1994; Noce 1995; Carneiro et al 1995; Machado et al 1996 etc). No Neoarqueano, um evento tectonomagmático (o Evento Rio das Velhas) teria ocorrido no período de 2.780 - 2.700 Ma, quando a crosta TTG preexistente (de idade entre 3,38 e $2,86 \mathrm{Ga}$ ) foi intensamente retrabalhada e invadida por rochas graníticas cálcio-alcalinas, assim como félsicas. Para vulcanismo e sedimentação do cinturão de rochas verdes do SRV, Carneiro (1992) sugere um processo de fechamento de uma bacia oceânica e posterior colisão continental. $\mathrm{O}$ processo representaria a aglutinação de vários núcleos siálicos que culminaria com a formação do atual embasamento arqueano do QF (Noce et al 1994; Teixeira et al 1994; Carneiro et al. 1996). Com base nas características litoestratigráficas e nas idades de zircões detríticos das rochas do SRV, Machado et al (1996) descrevem para o cinturão de rochas verdes um ambiente de arco de ilhas que teria se formado sobre um antigo

* Departamento de Geologia, Escola de Minas, Universidade Federal de Ouro Preto - Morro do Cruzeiro, 35.400-000 Ouro Preto - MG - Brasil -

Fax: (031) 559 1605; e-mail: caroline@degeo.ufop.br

** e-mail: mauricio@degeo.ufop.br

*** e-mail: issamu@degeo.ufop.br

****marco@degeo.ufop.br

*****Bolsista Iniciação Científica / CNPq 


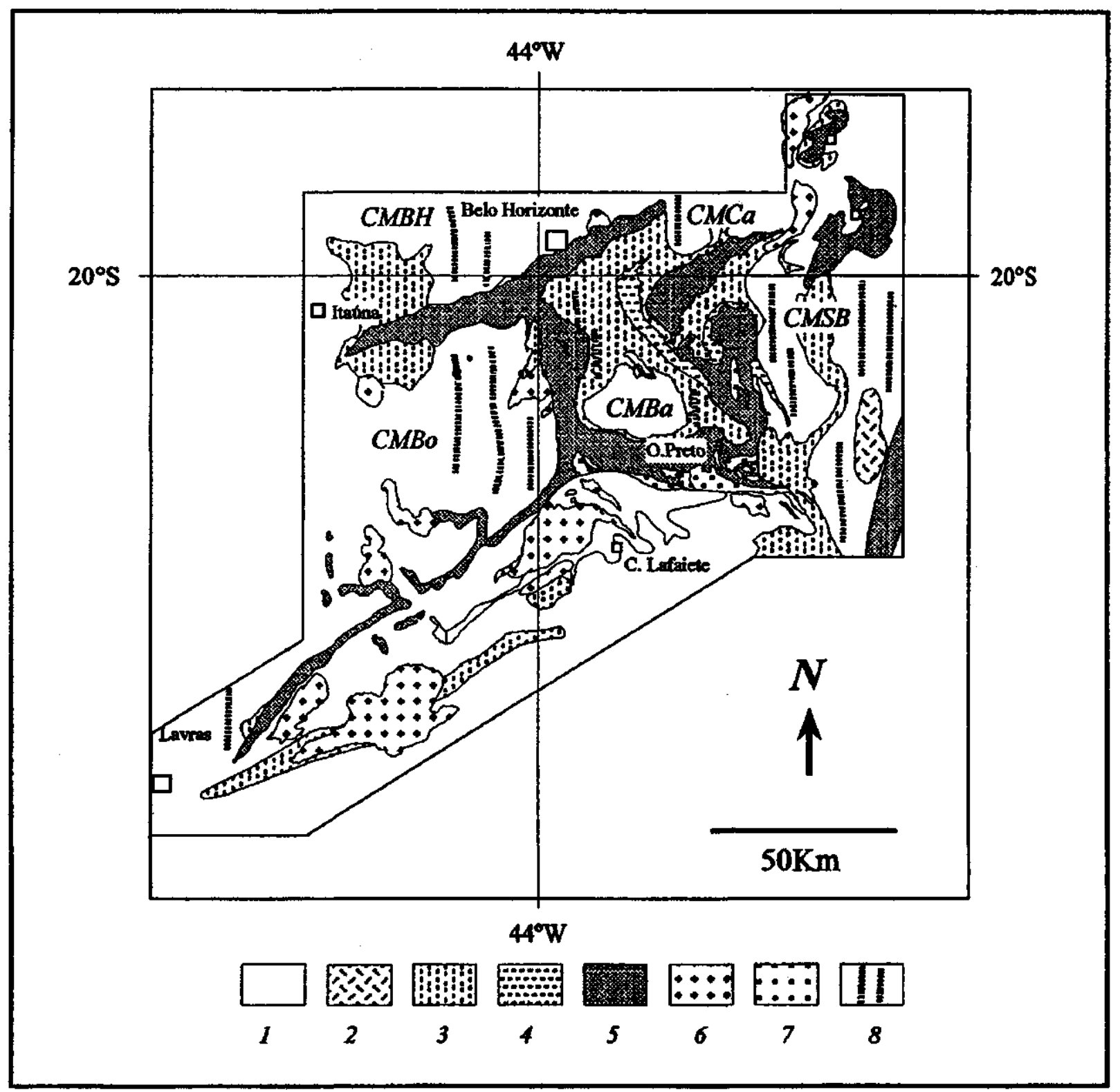

Figura 1: Mapa geológico simplificado do Quadrilátero Ferrífero, no Estado de Minas Gerais (modificado de Endo \& Carneiro 1996 e Endo 1997). 1- Embasamento arqueano retrabalhado ou não; 2- Complexo Granulítico Acaiaca; 3- Sequência do tipo greenstone belt de idade arquearia (Rio das Velhas, Barbacena e Piumhi); 4- Grupo Maquine; 5- Supergrupo Minas e Grupo Dom Silvério; 6- Granitóides arqueanos e paleoproterozóicos; 7- Grupo Itacolomi; 8- Foliação gnáissica N-S. Complexos Metamórficos Bonfim (CMBo), Bação (CMBa), Belo Horizonte (CMBH), Caetés (CMCa) e Santa Bárbara (CMSB).

Figure 1: Simplified geologic map of the Quadrilátero Ferrífero, in the State of Minas Gerais (modified after Endo \& Carneiro 1996 and Endo 1997). 1- Archean basement, partially reworked; 2- Acaiaca Granulitic Complex; 3- Greenstone belt sequence of Archean age (Rio das Velhas, Barbacena e Piumhi); 4- Maquine Group; 5- Minas Supergroup and Dom Silvério Group; 6- Archean and paleoproterozoic granitoids; 7- Itacolomi Group; 8- N-S gnaissic foliation. Metamorphic Complexes: Bonfim - CMBo; Bação - CMBa; Belo Horizonte - CMBH; Caetés - CMCa; Santa Bárbara - CMSB;

bloco continental, área-fonte dos sedimentos detríticos, pósvulcanismo do SRV.

Em estudos recentes, Endo \& Carneiro (1996), Endo et al. (1996a) e Endo et al. (1996b) sugerem, para o Neoarqueano, uma tectônica transpressional. Eles descrevem uma foliação milonítica de direção NS, subvertical, e indicadores cinemáticos com componente direcional, caracterizando movimentos nos dois sentidos, dextral e sinistral. A foliação milonítica, NS, foi reconhecida tanto nos complexos metamórficos quanto nas rochas do SRV (Fig. 1).

Segundo Endo \& Carneiro (1996), Endo et al. (1996a) e Endo et al. (1996b), uma "matriz estrutural NS" caracterizaria a evolução tectônica do Neoarqueano no QF. A direção preferencial NS, reconhecida nas rochas arqueanas, exibe, no entanto, fluxos heterogéneos em alguns domínios. Isto ocorre, por exemplo, em torno do Complexo Metamórfico do Bação (CMBa), considerado como um alto estrutural, onde as estruturas NS sofrem variados graus de deflexão. Neste domínio, uma foliação milonítica contorna o complexo deixando registros, também, em toda a sua borda interna. Endo et al. (1996a) e Endo (1997) fazem uma interpretação da trajetória da foliação milonítica resultante do Evento Rio das Velhas, no Neoarqueano (Fig. 2) e mostram que, nas porções a NW e $\mathrm{SE}$ do CMBa, a transição entre o plano de fluxo NS regional 

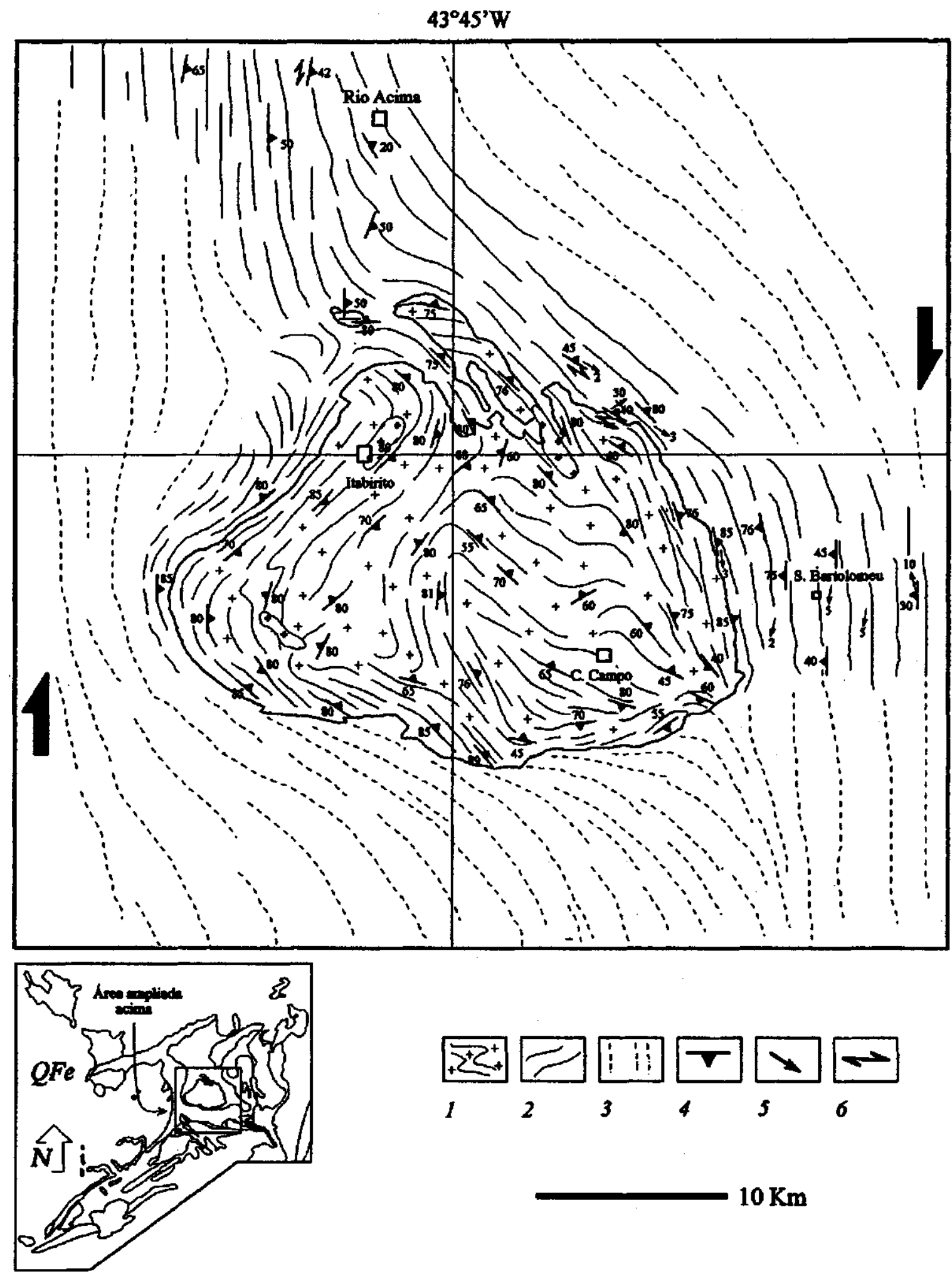

$10 \mathrm{Km}$

Figura 2: Mapa interpretativo da trajetória da foliação milonítica neoarqueana no Supergrupo Rio das Velhas e no Complexo Metamórfico do Bação. As setas indicam o sentido do movimento direcional principal (modificado de Endo et al. $1996 a$ e Endo 1997). 1- Complexo Metamórfico do Bação com a trajetória dafoliação gnáissica milonítica; 2- Trajetória da foliação milonítica no Grupo Nova Lima; 3- Potenciais trajetórias da foliação milonítica no Grupo Nova Lima em áreas hoje recobertas pelo Supergrupo Minas e pelo Grupo Maquine; 4- Foliação milonítica; 5- Lineação de estiramento mineral; 6- Deslocamento lateral direito.

Figure 2: Interpretative map of the form Unes of the Neoarchean mylonitic foliation in the Rio das Velhas Supergroup and in the Bação Metamorphic Complex. Arrows indicate the main sense of movement (modified after Endo et al 1996a and Endo J997). 1- Bação Metamorphic Complex with gneiss mylonitic form Unes; 2- Mylonitic form Unes in the Nova Lima Group; 3- Potential mylonitic form Unes in the Nova Lima Group recovered by rocks of the Maquine Group and the Minas Supergroup; 4-Mylonitic foliation; 5-Mineral stretching lineation; 6-Right-lateral deslocation. 
e a foliação em torno do complexo, configura pontos tríplices no sentido de Brun \& Pons (1981). Dorr (1969) e Oliveira et al. (1997) descrevem estruturas primárias do tipo estratificação cruzada nos metassedimentos arqueanos, polideformados do SRV, preservadas a NW do CMBa, na altura dos

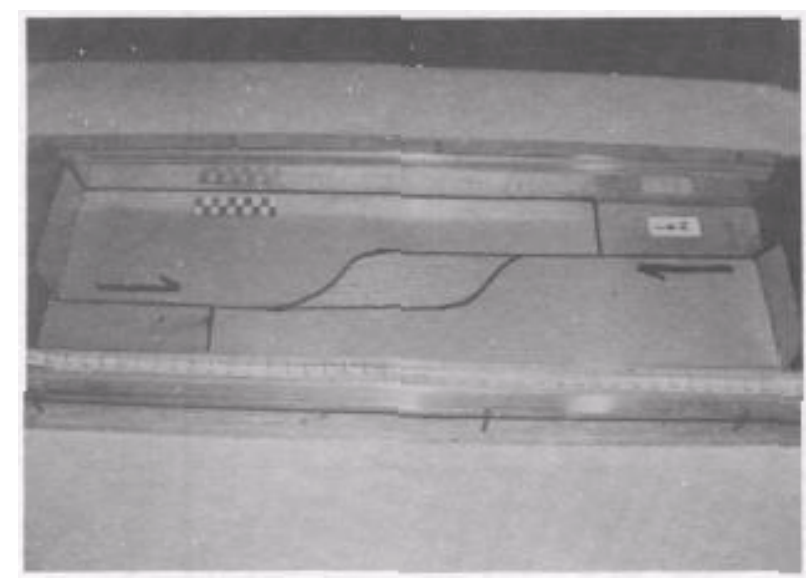

Figura 3: Fotografia da caixa de experimentos. A escala representa $5 \mathrm{~cm}$.

Figure 3: Photograph ofthe experimental box. The scale represents $5 \mathrm{~cm}$.
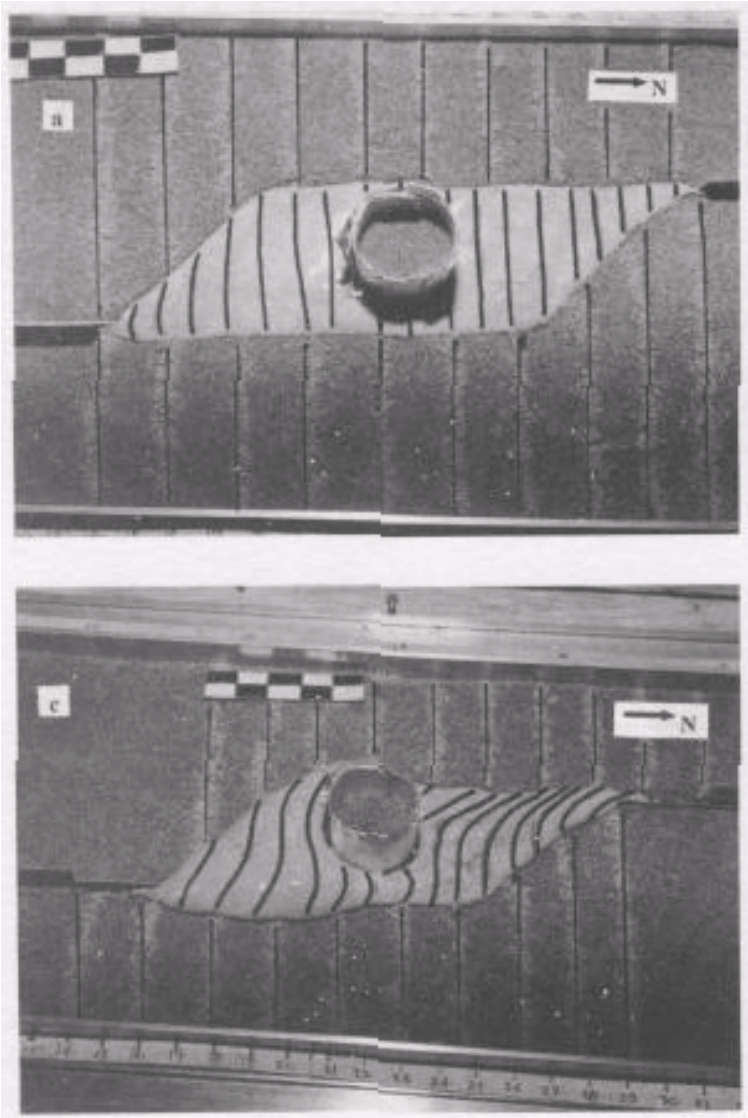

pontos tríplices que funcionam como domínios de baixa pressão.

As feições citadas justificam uma tectônica dextral que, segundo Éndo et al. (1996a) remontaria ao episódio deformacional mais antigo do evento transpressional. Os autores preconizam, ainda, um segundo e um terceiro episódio de reativação da matriz estrutural NS, onde os componentes direcionais seriam, respectivamente, sinistral e dextral.

O modelo da tectônica transpressional neoarqueana explica, pela primeira vez, de maneira satisfatória, as mesoestruturas observadas nas bordas internas e na região imediatamente circunvizinha ao CMBa. Neste domínio, lineações de estiramento sub-horizontais ocorrem sobre uma foliação milonítica, em geral de alto ângulo. Gomes \& Eisele (1993) e Gomes \& Baptista (1994) descrevem na borda do CMBa uma zona de cisalhamento transcorrente predominantemente sinistrai mas com registros de movimento dextral.

OBJETIVO DO TRABALHO E CONDIÇÕES DE CONTORNO O objetivo do presente trabalho é testar, através de experimentos físicos, a aplicabilidade mecânica e cinemática do modelo tectônico de Endo \& Carneiro (1996), o qual preconiza para o Neoarqueano, uma transpressão NS no QF. Os experimentos visam simular a deformação transpressional dextral no domínio do $\mathrm{CMBa}$, onde se encontram os seus registros mais evidentes.

A modelagem física analógica, que tem o intuito de simular a evolução de sistemas de estruturas geológicas, requer, para o seu sucesso, que se simplifiquem as condições de contorno
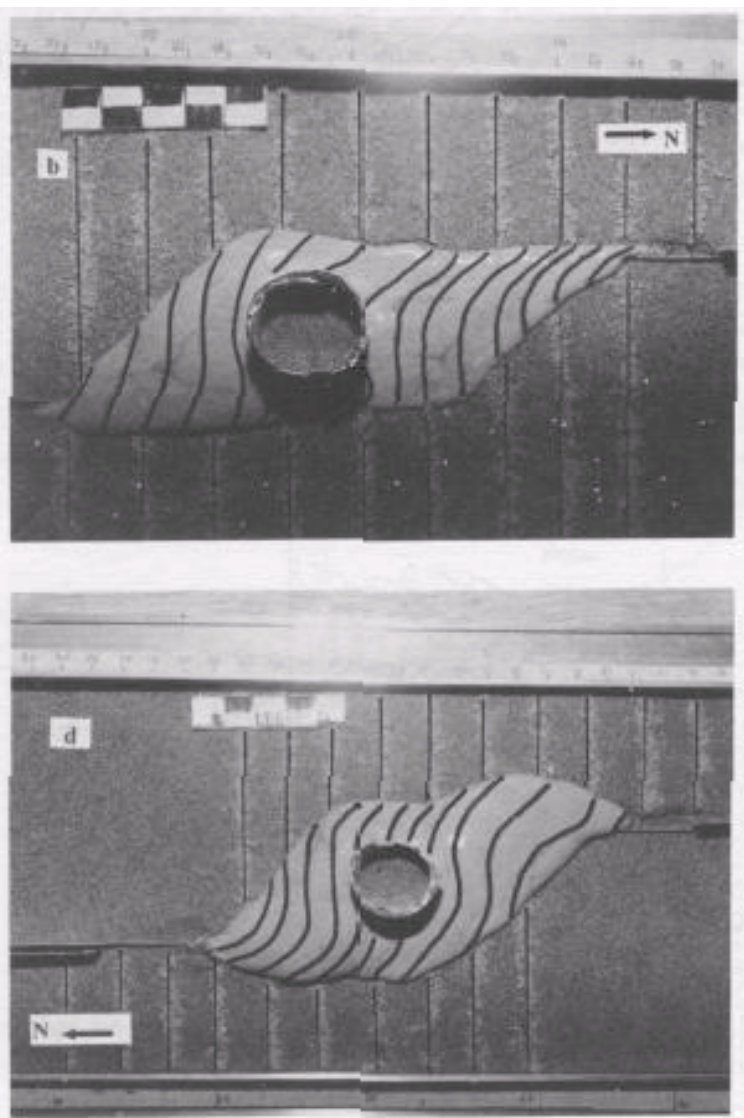

Figura 4: Fotografias mostrando o experimento 1, antes e após vários estágios da deformação progressiva, (a) O experimento antes da deformação, (b) após $5 \%$ de movimento direcional dextral da placa oeste, (c) após $10 \%$ de movimento da placa oeste e (d) após 15\% de movimento direcional dextral, $10 \%$ da placa oeste e 5\% da placa leste. A escala representa 5 cm. Figure 4: Photographs showing experiment 1, before and after several stages of progressive deformation. (a) The experiment before defonnation, (b) after 5\% of dextral strike-slip of the west plate, (c) after 10\% of movement of the west plate and (d) after $15 \%$ of dextral strike-slip, $10 \%$ of the westplate and $5 \%$ of the east plate. The scale represents $5 \mathrm{~cm}$. 

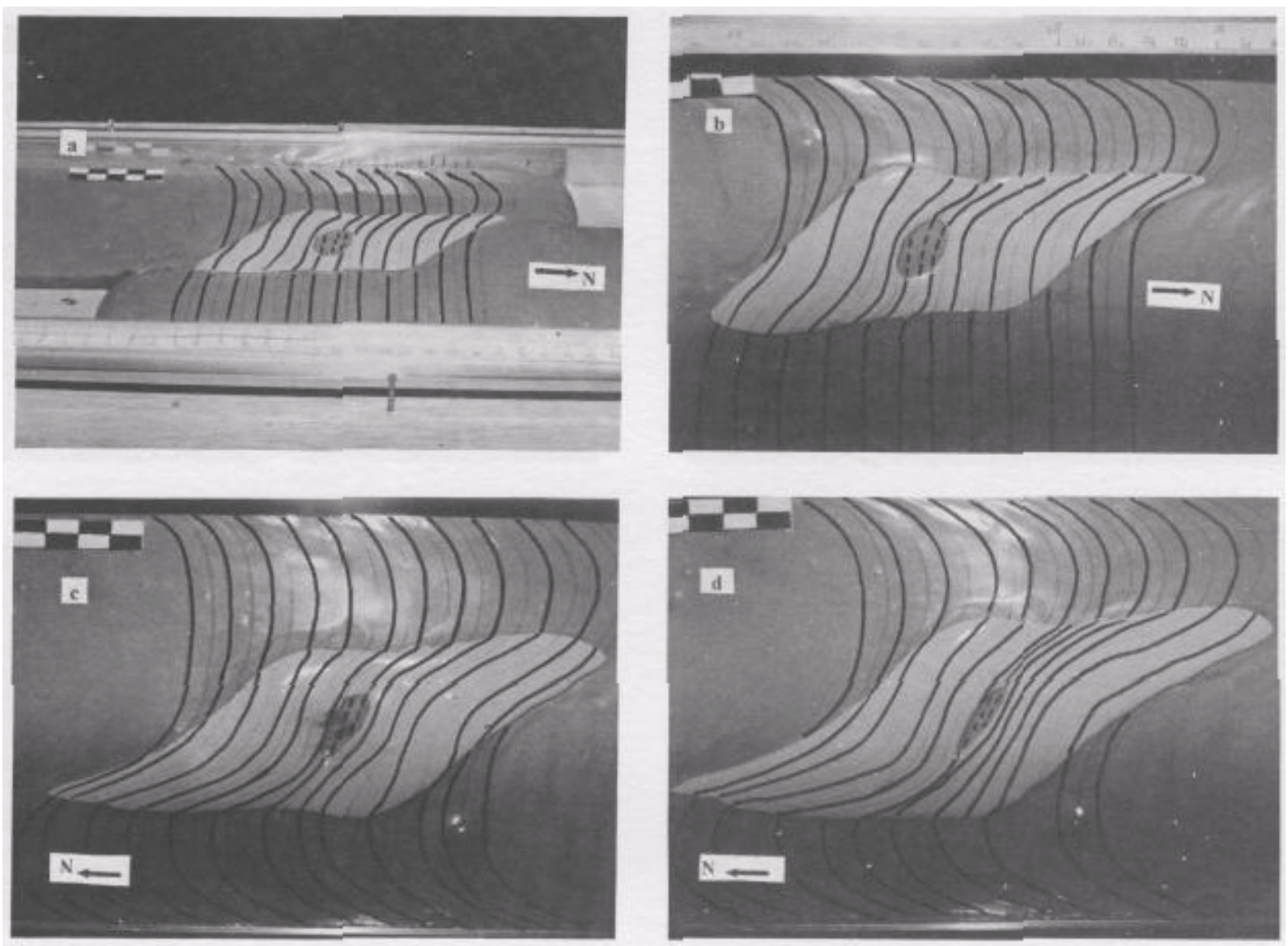

Figura 5: Fotografias mostrando estágios progressivos da deformação do experimento 2. (a) O experimento após 5\% de movimento direcional dextral da placa oeste, (b) após 10\% de movimento da placa oeste, (c) após 15\% de movimento direcional dextral, 10\% da placa oeste e $5 \%$ da placa leste e (d) após $20 \%$ de movimento direcional dextral, $10 \%$ da placa oeste e $10 \%$ da placa leste. A escala representa $5 \mathrm{~cm}$.

Figure 5: Photographs showing stages of progressiva deformation of experiment 2. (a) The experiment after 5\% of dextral strike-slip of the west plate, (b) after $10 \%$ of movement of the west plate, (c) after $15 \%$ of dextral strike-slip, $10 \%$ of the west plate and $5 \%$ of the east plate and (d) after $20 \%$ of dextral strike-slip, $10 \%$ of the west plate and $10 \%$ of the east plate. The scale represents $5 \mathrm{~cm}$.

dos modelos tectônicos. Assim, sem preocupação especial com um modelo para explicar a origem do cinturão de rochas verdes do SRV, trabalhou-se simplesmente com a hipótese de que este estaria encaixado em uma crosta siálica, mais antiga. Supõe-se uma geometria alongada para o cinturão, no caso NS, com um fragmento de crosta siálica no seu interior, representando o CMBa. Para o embasamento, cujas verdadeiras condições reológicas no Neoarqueano são desconhecidas, empregou-se, em três experimentos diferentes, materiais analógicos variados, com o objetivo de simular a crosta tanto rúptil quanto dúctil.

Os experimentos foram executados em caixas retangulares de $40 \times 13 \times 2 \mathrm{~cm}$ (comprimento x largura $\times$ altura). Sobre a base das caixas montou-se o embasamento, cada experimento com um determinado material analógico, introduzindo-se, neste, silicone puro (Rhône-Poulenc) para simular o SRV, de comportamento dúctil. Assumiu-se que, durante a deformação, os contatos entre o embasamento e o cinturão de rochas verdes representariam zonas de fraqueza preexistentes, com forte influência sobre a cinemática direcional. Para satisfazer esta premissa, duas placas finas e rígidas foram instaladas sob o material analógico, que representa a crosta siálica, de maneira a moldar um sistema de transcorrência curvo (Fig. 3). Dentro do silicone, o CMBa foi representado por um corpo de geometria cilíndrica constituído pelo mesmo material que a crosta siálica.
Ao final da montagem de cada experimento, linhas de direção EW, normais ao movimento transcorrente, foram desenhadas sobre os materiais analógicos, com o objetivo de ilustrarem a deformação progressiva.

Cada uma das placas do embasamento foi deslocada por 4 $\mathrm{cm}$ na direção NS perfazendo um encurtamento total de $20 \%$.

No primeiro experimento, simulou-se uma crosta siálica de comportamento rúptil, empregando-se areia seca. Vendeville et al. f 1987) demonstram que as propriedades mecânicas da areia seca permitem o seu uso como material analógico para modelar a deformação rúptil da crosta rasa. A areia seca, peneirada e colorida artificialmente, é utilizada para esta finalidade, com grande frequência em modelos físicos.

No segundo e no terceiro experimento simulou-se uma crosta siálica dúctil. Diferentes trabalhos de pesquisa descrevem o uso de silicone (material de comportamento newtoniano) para modelar a deformação que envolve a crosta inferior ou, também, a astenosfera. Além disto, o silicone é utilizado em experimentos que simulam a deformação em bacias sedimentares caracterizadas pela presença de evaporitos. Para o objetivo do presente trabalho, o silicone demonstrou possuir viscosidade baixa demais $\left(10^{5}\right.$ poises, à temperatura ambiente). Na ausência de um material analógico adequado para a deformação dúctil no modelo tectônico em estudo, optou-se por testar o comportamento de misturas de silicone com outros materiais. 

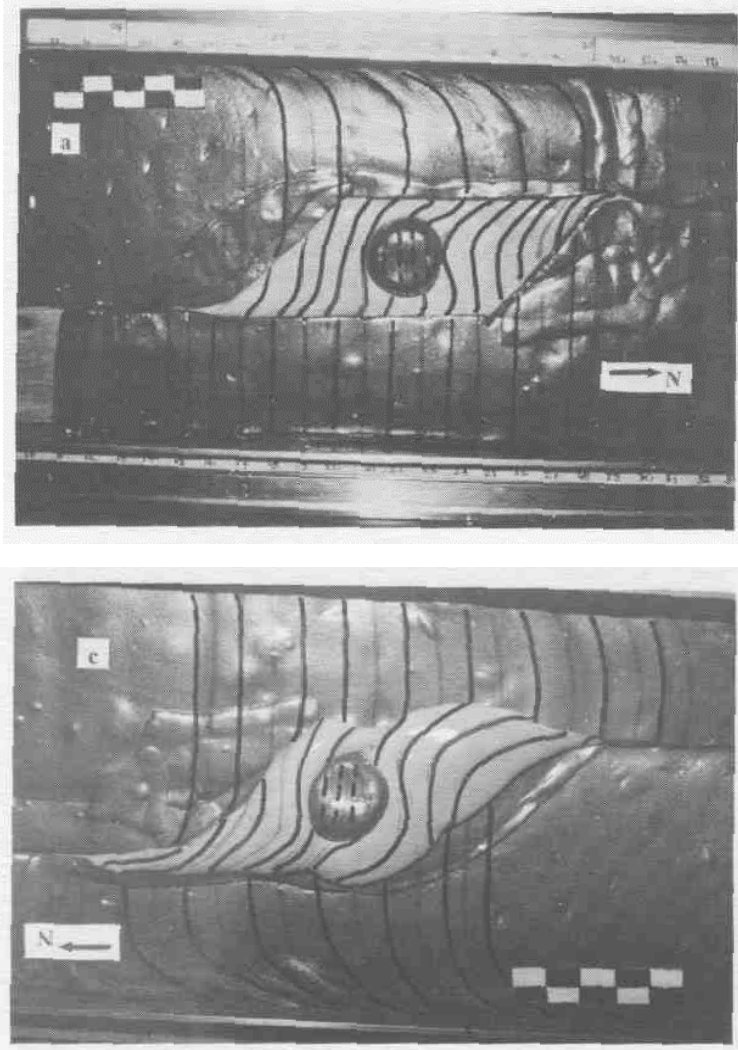
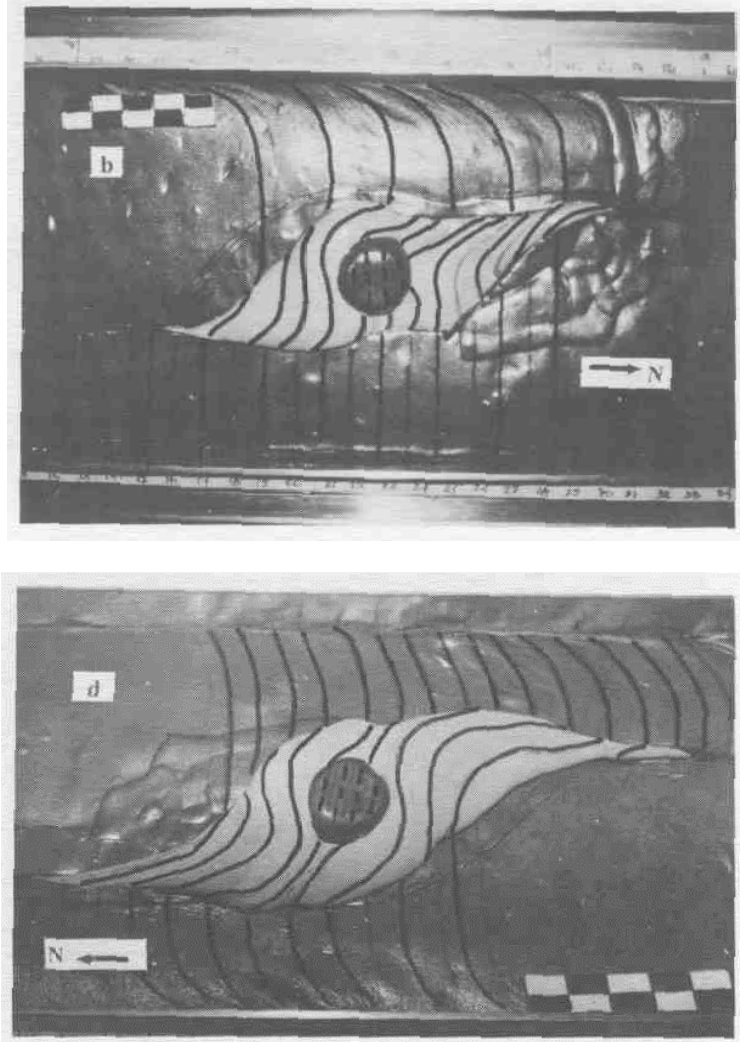

Figura 6: Fotografias mostrando estágios progressivos da deformação do experimento 3. (a) O experimento após 5\% de movimento direcional dextral da placa oeste, (b) após 10\% de movimento da placa oeste, (c) após 15\% de movimento direcional dextral, 10\% da placa oeste e $5 \%$ da placa leste e (d) após $20 \%$ de movimento direcional dextral, $10 \%$ da placa oeste e $10 \%$ da placa leste. A escala representa $5 \mathrm{~cm}$.

Figure 6: Photographs showing stages of progressive deformation of experiment 3. (a) The experiment after 5\% of dextral strike-slip of the west plate, (b) after $10 \%$ of movement of the west plate, (c) after $15 \%$ of dextral strike-slip, $10 \%$ of the west plate and $5 \%$ of the east plate and (d) after $20 \%$ of dextral strike-slip, $10 \%$ of the west plate and $10 \%$ of the east plate. The scale represents $5 \mathrm{~cm}$.

Pesquisaram-se diferentes misturas de silicone com pó de grafite. Assim, empregou-se para o experimento 2, uma mistura silicone/pó de grafite na proporção $3: 1$, e para o experimento 3 outra mistura na proporção $1: 1$. Testes empíricos, simples, forneceram a viscosidade relativa das misturas silicone/grafite $3: 1$ e $1: 1$, de 17 e $56 \%$ superiores àquela do silicone puro, respectivamente.

DESCRIÇÃO DOS EXPERIMENTOS As figuras 4, 5 e 6 ilustram várias fases da deformação transpressional dextral nos três modelos. Cada fase representa um incremento de $5 \%$ (2 cm) na deformação progressiva até um máximo de $20 \%$ (8 $\mathrm{cm})$.

O experimento 1 , que simula a tectônica transcorrente em uma crosta rúptil, é apresentado na figura 4 . Após $5 \%$ de movimento direcional dextral da placa oeste (Fig. 4b), o silicone sofre estiramento no domínio NW de sua área de ocorrência, causando arrasto das linhas de referência para a direção NS. Além disto, o silicone mostra forte espessamento na porção SW. Nota-se, também, uma inflexão das linhas de referência em torno do CMBa formando pontos tríplices na porção NW e SE, como previsto no modelo teórico de Endo \& Carneiro (1996) e Endo et al. (1996a). As linhas de fluxo, no silicone, que contornam o alto estrutural do $\mathrm{CMBa}$, coincidem com os traços da foliação metamórfica do Supergrupo Rio das Velhas.
As feições estruturais descritas no silicone se acentuam com a deformação progressiva (Fig. 4c), enquanto na areia, material que simula a crosta siálica, nenhuma deformação é constatada. Ao longo da placa de areia ocorre transcorrência pura. O experimento é interrompido após $15 \%$ de movimento direcional, quando o forte espessamento do silicone causa fluxo viscoso por cima da areia adjacente (Fig. 4d). A grande diferença de competência entre areia e silicone puro, evidencia uma partição da deformação do tipo transpressão dominado por cisalhamento puro ("pure shear dominated transpression") no sentido de Tikoff \& Teyssier (1994). A componente do cisalhamento puro é absorvida, por completo, pelo escape ascensional verificado no silicone, enquanto o cisalhamento simples afeta mais fortemente o material rúptil, a crosta, mas com influência sobre o material viscoso.

$\mathrm{O}$ experimento 2 , efetuado com placas de crosta constituídas pela mistura silicone/pó de grafite 3:1 (material 17\% mais viscoso do que o silicone puro), revelou comportamento excessivamente plástico. A figura 5 mostra a deformação, em estágios progressivos de $5 \%$, até o máximo de $20 \%$, de movimento direcional dextral. Observa-se, nas placas siálicas, forte deformação por arrasto dúctil enquanto o $\mathrm{CMBa}$ sofre um contínuo achatamento na direção NW-SE. No silicone ocorre arrasto das linhas de fluxo ao longo dos contatos com o embasamento e deflexão em torno do $\mathrm{CMBa}$. Neste experimento, que simula crosta e supracrustais de propriedades mecânicas similares, o efeito da partição da deformação di- 
EVENTORIODASVELHAS
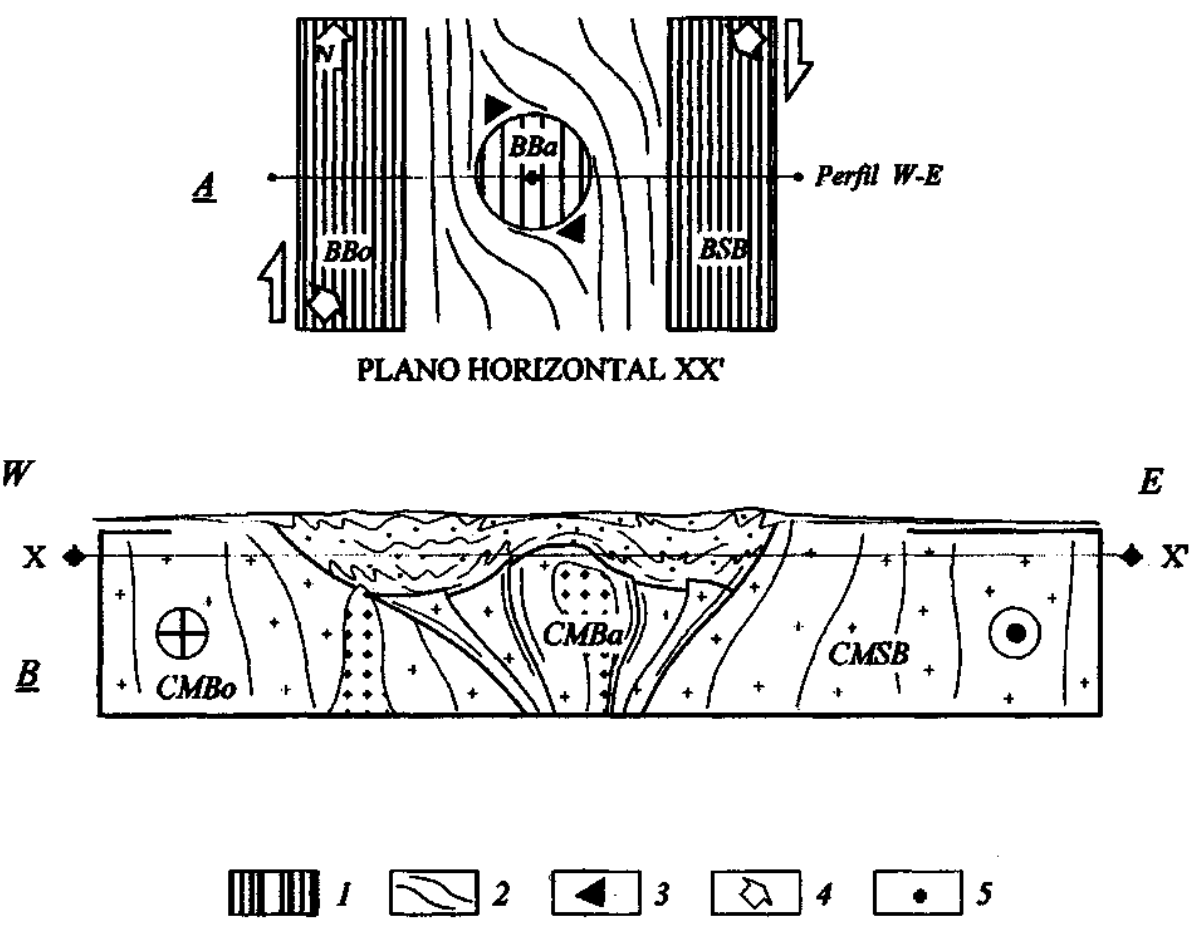

Figura 7: Esquema da deformação transpressional dextral mais antiga do Evento Rio das Velhas (modificado de Endo 1977). AModelo, em planta, da tectônica dextral do Supergrupo Rio das Velhas com indicação do eixo máximo de estiramento vertical; B-Perfil esquemático do domínio do Complexo Metamórfico do Bação após o Evento Rio das Velhas, 1- blocos rígidos (Bloco Bonfim - Bbo, a oeste, Bloco Bação - BBa, no centro e Bloco Santa Bárbara - BSB, a leste); 2- traço da foliação milonítica; 3pontos tríplices defoliação no sentido de Bruns \& Pons (1981); 4- vetor compressivo do sistema transpressional; 5- eixo máximo de estiramento vertical da zona de cisalhamento transpressional. Complexo Metamórfico do Bonfim - CMBo; do Bação - CMBa; de Santa Bárbara - CMSB.

Figure 7: Schematic illustrations of the oldest dextral transpressional deformation of the Rio das Velhas Event (modified from Endo 1977). A- Deformation model of the dextral shear in the Rio das Velhas Supergroup, in map view, with indication of the vertical maximum stretching axis. B-Section of the Bação Metamorphic Complex domain after the Rio das Velhas Event. 1- rigid blocks (Bonfim Block - Bbo, at the west side, Bação Block - Bba, in the center, Santa Bárbara Block $\mathrm{BSB}$, at the east side); 2- mylonitic foliation trajectory; 3- triple points of the mylonitic foliation (see Bruns \& Pons 1981); 4- component of horizontal shortening of the transpressional system; 5-vertical maximum stretching axis of the shear zone. Metamorphic Complexes: Bonfim - CMBo; do Bação - CMBa; de Santa Bárbara - CMSB.

minui. A crosta também sofre deformação por cisalhamento puro que, nas placas, se manifesta por escape ascensional e, no CMBa, por escape lateral ou estiramento (NW-SE). A componente de cisalhamento simples produz, no corpo cilíndrico, uma rotação no sentido horário, e nas placas um fluxo direcional.

A transpressão no $\mathrm{QF}$, no experimento 3, realizada com uma mistura silicone/grafite 1: 1 (Fig. 6) simula uma crosta de propriedades mecânicas intermediárias entre aquelas dos experimentos 1 e 2 . Observa-se, nas placas siálicas, leve arrasto plástico e espessamento mínimo, e, no cilindro que representa o $\mathrm{CMBa}$, uma torção no sentido horário. O silicone revela, ao final da deformação, como no experimento 1 , forte escape ascensional.

DISCUSSÃO Os três experimentos forneceram bons resultados para a simulação da deformação nas rochas do SRV, vista em planta. O silicone, de baixa viscosidade, simula com sucesso as estruturas representadas no mapa da figura 2, geradas por um movimento direcional dextral. As linhas de referência $\mathrm{E}-\mathrm{W}$, que ilustram o fluxo do material durante a deformação, posicionam-se, por rotação e estiramento, para a direção NS. Além disto, o movimento direcional causa uma deformação na região circunvizinha ao alto estrutural do
CMBa, expressa pelo desvio das linhas de referência que o contornam, gerando pontos tríplices nas porções SE e NW. Dependendo do material analógico empregado para a crosta, a deformação afeta também o CMBa, por rotação ou estiramento.

O experimento 1 , caracterizado por forte escape ascensional de massas, demonstra o efeito da componente do cisalhamento puro, na transpressão. Endo (1997) sugere para a primeira fase de soerguimento do $\mathrm{CMBa}$, relacionável ao evento tectônico transpressional dextral (Orogênese Rio das Velhas), um processo deste tipo. Como mostram os esquemas da figura 7, o autor sugere para a ascensão do $\mathrm{CMBa}$, considerado originalmente como sendo o embasamento da bacia do SRV, um movimento transpressional dos blocos adjacentes, o "Bloco Bonfim" e o "Bloco Santa Barbara". Esta hipótese encontra respaldo assumindo-se para o SRV e o seu embasamento profundo, condições reológicas mais dúcteis do que para a crosta aflorante. Vale lembrar, que o grau metamórfico descrito para as rochas do CMBa é mais elevado do que aquele constatado nas supracrustais adjacentes. Desta maneira, o experimento 1 , explicaria a ascensão do $\mathrm{CMBa}$, por fluxo vertical.

Entre os experimentos 2 e 3, nos quais foram empregados para a simulação das placas siálicas, as misturas sili- 
cone/grafite, viscosas, o experimento 3 logrou melhor êxito quanto à forma atual, em planta, do CMBa aflorante. Em ambos, o movimento transcorrente de $20 \%$ gera, nas placas, arrasto das linhas de referência para a direção NS. No experimento 2, no entanto, ocorre simultaneamente forte achatamento do CMBa, na direção NW-SE. Um achatamento deste tipo não se constata na geometria atual do $\mathrm{CMBa}$, no entanto, a presença de corpos graníticos de orientação NW$\mathrm{SE}$, nas porções NE e SW do complexo, sugerem, segundo Endo (1997), uma possível relação com o episódio transpressional dextral. $\mathrm{O}$ encurtamento em NE-SW poderia gerar ou uma zona de extensão segundo NW-SE ou fraturas de tração NE-SW, rotacionadas progressivamente.

No material mais viscoso, da mistura silicone/grafite 1:1, experimento 3, o achatamento do $\mathrm{CMBa}$ é desprezível, manifestando-se uma torção horária deste corpo. A torção horária do $\mathrm{CMBa}$, observada no experimento 3 , em primeira análise não condiz com o movimento 'transcorrente predominantemente sinistral mas com registros de movimento horário' descrito por Gomes \& Eisele (1993) na borda do complexo. Uma explicação plausível para o movimento conflitante detectado no campo e no laboratório, seria a possível obliteração parcial das estruturas do primeiro episódio do evento transpressional dextral, simulado no presente estudo, pelo segundo episódio sinistral descrito por Endo et al. (1996a).

Bruns, J. P. \& Pons, J. 1981. Strain patterns of pluton emplacement in a crust undergoing non-coaxial deformation, Sierra Morena, Southern Spain Journal of Structural Geology, 3:219-229.

Carneiro, M. A. 1992. O Complexo Metamórfico Bonfim Setentrional (Quadrilátero Ferrifero, Minas Gerais): litoestratigrafia e evolução geológica de um segmento de crosta continental do Arqueano. São Paulo. 225 p. (Tese de Doutoramento, Instituto de Geociências, Universidade de São Paulo)

Carneiro, M. A., Noce, C. M. \& Teixeira, W. 1995. Evolução policíclica do Quadrilátero Ferrífero: uma análise fundamentada no conhecimento atual da geocronologia U-PB e geoquímica isotópica Sm-Nd. Revista Escola Minas, 48:264-273.

Carneiro, M. A., Teixeira, W., Noce, C. M. \& FERNANDES, R. A. 1996. Archean growth process in the Quadrilátero Ferrífero: a geochronological U-Pb and Sm-Nd approach to the Rio das Velhas event (2780-2700 MA). In Symposium Archaean Terranes of the south american Platform, Brasília, 1996. Extended Abstracts, Brasília, SBG, P. 59-60.

Dorr, J. V. N. 1969. Physiographic, stratigraphic and structural development of the Quadrilátero Ferrífero, Brazil. U. S. Geol. Surv. Prof. Paper, 641 (A): 110p.; Washington.

Endo, L; Carneiro, M. A. \& Machado, R. 1996a. O Complexo Metamórfico do Bação: um elemento estrutural anisotrópico na deformação do Supergrupo Rio das Velhas - QF, MG. In: Congresso Brasileiro de Geologia, 39, Salvador, 1996. Anais..., Salvador, SBG V. 1, P. 411-413.

Endo, I. \& Carneiro, M. A. 1996. O regime tectônico no Neoarqueano no Quadrilátero Ferrífero: um modelo transpressional. In: Congresso Brasileiro de Geologia, 39, Salvador, 1996. Anais..., Salvador, SBG V. 1, P. 414-416.

Endo, L; Fonseca, M. A. \& Oliveira, C. G. 1996b. Tectônica transcorrente NS de idade neoarqueana no Quadrilátero Ferrífero, MG. In: Congresso Brasileiro de Geologia, 39, Salvador, 1996. Anais..., Salvador, SBG V. 1, P. 437-439.

Endo, I. 1997. Regimes tectônicos do Arqueano e Proterozóico no interior da Placa Sanfranciscana: Quadrilátero Ferrífero e áreas adjacentes, $M G$ Brasil. São Paulo (Tese de Doutoramento, Instituto de Geociências, Universidade de São Paulo)

Endo, I. \& Machado, R. 1997. Regimes tectônicos no segmento meridional do Cráton do São Francisco: Região do Quadrilátero Ferrífero, Minas Gerais In: Simpósio de Geologia de Minas Gerais, 9, Ouro Preto, 1997, Anais... Ouro Preto, SBG/ Núcleo MG (submetido).

Figueiredo, M. C. H. \& Barbosa, J. S. F. 1993. Terrenos metamórficos de alto grau do Cráton do São Francisco. In: Dominguez, J. M. L. \& Misi A. eds. $O$ Cráton do São Francisco, SBG, p. 63-84.

Golia, A. 1977. Petrografia e Geoquímica dos metassedimentos do Grupo Nova Lima, Greenstone Belt Rio das Velhas na região de São Bartolomeu: modelagem de área-fonte, proveniência e ambiente tectônico. Ouro Preto. 142 p. (Tese de Mestrado, Departamento de Geologia, Universidade Federal de Ouro Preto)

Gomes, C. J. S. \& Eisele, R. 1993. A deformação em uma zona de cisalhamento descontínua na borda do Complexo do Bação, Quadrilátero Ferrífero, Minas Gerais. Revista Brasileira de Geociências, SBG, 23:124-128.
Não cabe a este trabalho experimental, uma conclusão sobre as propriedades mecânicas da crosta siálica durante o Neoarqueano, mas, apenas mostrar possíveis implicações de cada experimento. Ô experimento que melhor reflete a geometria atual das estruturas na região centro sul do QF é o experimento 3. No entanto, os experimento 1 e 2 mostram feições que se encaixam perfeitamente no modelo transpressional dextral, a partir de condições reológicas diferentes. A comparação entre o mapa da trajetória da foliação milonítica para a tectônica pré-Minas (Fig. 2) e o estágio final da deformação do experimento 3 (Fig. 6e), demonstram que é perfeitamente viável assumir para o Neoarqueano, um modelo tectônico de cisalhamento direcional, com uma ou mais fases de reativações plano-paralelas. As modelagens sugerem para a tectônica neoarqueana, uma magnitude de deformação de no mínimo $20 \%$, e para a reologia das rochas supracrustais um comportamento dúctil.

Agradecimentos Os autores desejam expressar os seus agradecimentos ao Conselho Nacional de Desenvolvimento Científico e Tecnológico - CNPq (processo n. 523045/95-6) e à Fundação de Amparo à Pesquisa do Estado de Minas Gerais - FAPEMIG (processo n . 908/95) pelo auxílio financeiro que tornou possível a realização deste trabalho.

\section{REFERÊNCIAS}

Gomes, C. J. S. \& Baptista, E. I. 1994. A borda do Complexo Metamórfico do Bação: Deformação e Análise Estrutural. Revista Escola de Minas, 47:59-61.

Gomes, N. S. 1985. Petrologische und geochemische Untersuchungen im Bação-Komplex, Eisernes Viereck, Minas Gerais, Brasilien. Clausthal-Zellerfeld, 209p. (Tese de Doutoramento, Universidade Técnica de Clausthal)

Herz, N. 1970. Gneissic and igneous rocks of the Quadrilátero Ferrífero, Minas Gerais, Brazil. U. S. Geol. Surv. Prof. Paper, 641 (B): 58p.

Noce, C. M.; Machado, N. \& Teixeira, W. 1994. O Complexo Belo Horizonte e a evolução arqueana do Quadrilátero Ferrífero, Minas Gerais. In: Congresso Brasileiro de Geologia, 38, Camboriú, 1994. Boletim Resumos expandidos.... Camboriú, SBG V. 1, p. 68-69.

Noce, C. M. 1995. Geocronologia dos eventos magmáticos, sedimentares e metamórficos na região do Quadrilátero Ferrifero, Minas Gerais. São Paulo. 128p. (Tese de Doutoramento, Instituto de Geociências, Universidade de São Paulo)

Machado, N.; Schranck, A.; Noce, C. M. \& Gauthier, G. 1996. Ages of detrital zircon from Archean-Paleoproterozoic sequences: Implications for Greenstone Belt setting and evolution of a Transamazonian foreland basin in Quadrilátero Ferrífero, southeast Brazil. Earth and Planetary Sciences Letters, 141:259-276.

Oliveira, A. H.; Guitarrari, M. M.; Fonseca, M. A. \& Carneiro, M. A. 1997. Tectônica transcorrente compressiva (NE-SW) nas rochas do Supergrupo Rio das Velhas, na região de Itabirito, Minas Gerais. In: Simpósio de Geologia de Minas Gerais, 9, Ouro Preto 1997, Anais... Ouro Preto, SBG/ Núcleo MG (submetido).

Renger, F. E.; Noce, C. M.; Romano, A.W. \& Machado, N. 1994. Evolução sedimentar do Supergrupo Minas: 500Ma de registro geológico no Quadrilátero Ferrífero, Minas Gerais, Brasil. Geonomos, 2:1-11.

Roeser, H. M. P.; Alkmin, F. F.; Evangelista, H. J.: Coelho, J.; Menezes, M. G.; Varajão, C. C.; Souza, J. L.; Ferreira, C. M.; Gomes, N. S. 1987. Quadrilátero Ferrífero. In: Congresso Brasileiro de Geoquímica, 2 International Geochemical Congress, 13, Rio de Janeiro, 1989. Excursions... Rio de Janeiro, SBGq-CPRM/DNPM, p. 11-43.

Tikoff, B. \& Teyssier, C. 1994. Strain modeling of displacement-field partitioning in transpressional orogens. Journal of Structural Geology, 16:1575-1588.

Teixeira, W.; Carneiro, M. A.; Noce, C. M.; Machado, N.; Sato, K. \& Taylor, P. N. 1994. Pb, Sr and Nd isotope constraints on the archean evolution of gneissic-granitoid complexes in the southern São Francisco Cráton. Precambrian Research (in press)

Vendeville, B., Cobbold, P.R., Davy, P., Brun, J.P. \& Choukroune, P. 1987. Physical models of extensional tectonics at various scales. In: M. P. Coward, J. F.; Dewey \& Hanckok eds. Continental Extensional Tectonics, Geological Society of London, Special Publication, 28:95-107.

Manuscrito A-942

Recebido em 15 de outubro de 1997

Revisão dos autores em 22 de dezembro de 1997 Revisão aceita em 22 de dezembro de 1997 